\title{
Facial clefts in the west of Scotland in the period 1980-1984: epidemiology and genetic diagnoses
}

\author{
D R FitzPatrick, P A M Raine, J G Boorman
}

\begin{abstract}
Two hundred and eighty six cases of cleft lip, cleft palate, or both were identified in a study attempting complete ascertainment of babies with facial clefts born to women resident in the west of Scotland in a five year period beginning 1 January 1980. The total birth prevalence (TBP) of these defects over this period was 1.53 per 1000. The TBP for cleft lip with or without cleft palate (CL[P] was 0.74 per 1000 and for cleft palate (CP) was 0.79 per $1000 ; 26 \%$ of $C L[P]$ and $39 \cdot 5 \%$ of CP cases had one or more major congenital anomaly associated with their facial cleft and in over half of these cases a specific genetic or syndrome diagnosis could be made. In comparison to previous European reports this study shows a high incidence of associated abnormalities and a remarkably low ratio of $C L[P]: C P$ cases.
\end{abstract}

( $\mathcal{F}$ Med Genet 1994;31:126-129)

Cleft lip with or without cleft palate (CL[P] and cleft palate (CP) are aetiologically distinct subgroups of the facial cleft group of anomalies. This distinction has been made on the basis of the different embryological timings of primary and secondary palate closure ${ }^{1}$ and recurrence of the same type of defect within a family. ${ }^{2-5}$ There are also epidemiological differences between the groups which include an observed racial variation in the birth prevalence of $C L[P]^{6-9}$ but not $C P, 910$ an excess of male cases in most reports of the CL[P] group, ${ }^{21011}$ and a slight female excess in the CP group. ${ }^{1012}$ The higher incidence of associated congenital anomalies that has been reported in subjects with $\mathrm{CP}$ compared to those with $C L[P]^{1314}$ has also been cited as evidence of distinct aetiologies for these groups.

In spite of the differences between these groups there is evidence suggesting common factors in their aetiology. Woolf ${ }^{15}$ has shown a small but convincing increase in the occurrence of $\mathrm{CP}$ in the families of a large cohort of patients with CL[P]. Rintala ${ }^{16}$ reported a remarkable parallelism in the changes of birth prevalence of CL[P] and CP over a 27 year period in the Finnish population. It has also been noted that families with Van der Woude syndrome (MIM 119300) may have both types of defect associated with lip pits segregating in one pedigree ${ }^{17}$ Finally, a variation in the transforming growth factor $\alpha(\mathrm{TGF} \alpha)$ gene has been found to be over-represented in cohorts of unrelated subjects with both $\mathrm{CL}[\mathrm{P}]$ and CP. ${ }^{18-21}$

Previous reports of facial clefts in Scotland ${ }^{22}{ }^{23}$ have suggested that there is a relatively low incidence of CL[P] and high incidence of $\mathrm{CP}$ in this population compared to the European average. In the present study we have attempted complete ascertainment of babies born with facial clefts, within a five year period, to mothers living in the west of Scotland in order to calculate the birth prevalence of each subgroup. Particular attention was paid during the study to the number and nature of associated congenital anomalies and the specific genetic diagnosis in each of the subgroups. Data derived from this study are compared to those reported in other studies of European populations.

\section{Materials and methods}

The study population comprised those infants born to mothers whose main residence was within Greater Glasgow, Lanarkshire, Forth Valley, Dumfries and Galloway, Argyll and Clyde, or Ayrshire and Arran Health Boards from 1 January 1980 to 31 December 1984. The index cases were identified through four main sources; neonatal discharge forms, hospital admission records, the Glasgow database for European Registration for Congenital Anomalies and Twins (EUROCAT), and hospital diagnostic indices. Follow up information on index cases with associated abnormalities was obtained from personal examination, hospital records, genetic records, and detailed necropsy reports.

Patients with microforms of facial clefts (bifid uvula and submucous cleft palate) were excluded from the study group as the majority of these defects do not come to medical attention and would, therefore, require a population survey for complete ascertainment. ${ }^{245}$

A figure for birth prevalence was calculated, as the common occurrence of facial clefts in early spontaneous abortion $\mathrm{s}^{26}$ would make an incidence of these defects very difficult to estimate. Birth prevalence figures were calculated per 1000 total births $(\%$ TB) or live births $(\%$ LB) and quoted with $95 \%$ confidence intervals using the methods of Czeizel and Tusnady. ${ }^{27}$ Groups were compared using the $\chi^{2}$ test and the Yates correction factor was used in the two by two contingency tables $\left(\mathrm{YM} \chi^{2}\right)$. Evidence of cyclical trends within the facial clefts groups were assessed using both parametric $^{28}$ and non-parametric rank sum ${ }^{29}$ methods. Associated congenital anomalies were assigned to major and minor categories using the guidelines of Smith. ${ }^{30}$ 
Table 1 Birth prevalence of facial cleft subgroups

\begin{tabular}{lllll}
\hline Facial cleft & Total births & TBP & Live births & LBP \\
\hline CL[P] & 139 & $0.74(0 \cdot 12)$ & 126 & $0.68(0 \cdot 12)$ \\
CL & 51 & $0.27(0.08)$ & 51 & $0.27(0 \cdot 08)$ \\
CLP & 88 & $0.47(0 \cdot 10)$ & 75 & $0.41(0 \cdot 10)$ \\
CP & 147 & $0.79(0 \cdot 13)$ & 142 & $0.78(0 \cdot 13)$ \\
Total & 286 & $1.53(0 \cdot 18)$ & 268 & $1.44(0 \cdot 18)$ \\
\hline
\end{tabular}

$\mathrm{CL}=$ cleft lip only; $\mathrm{CLP}=$ cleft lip with cleft palate; $\mathrm{CL}[\mathrm{P}]=$ cleft lip with or without cleft palate; $\mathrm{CP}=$ cleft palate only; $\mathrm{TBP}=$ birth prevalence per 1000 total births (SD 2); LBP = birth prevalence per 1000 live births (SD 2).

\section{Results}

BIRTH PREVALENCE (TABLE 1)

Two hundred and eighty six patients with $\mathrm{CL}[\mathrm{P}]$ or CP were identified among the 187321 total births in the study population. The total birth prevalence (TBP) was thus estimated as $1.53 \pm 0 \cdot 18 \%$. Cleft lip occurred in $51 / 286(17.8 \%)$ of the cases, $88 / 286(30.8 \%)$ had cleft lip and palate (CLP), and 147/286 $(51.4 \%)$ had CP; $268 / 286(93.7 \%)$ of the facial cleft cases and $186139 / 187321$ (99.4\%) of total births were liveborn, so the live birth prevalence (LBP) can be calculated as $1.44 \pm 0 \cdot 18 \%$. Of the liveborn patients $51 / 268$ (19.0\%) had CL, 75/268 $(28.0 \%)$ had CLP, and $142 / 268(53.0 \%)$ had CP.

\section{NATURE OF CLEFT LIP DEFECT}

Of the 139 cases of CL[P] identified, 51/139 $(36.7 \%)$ had $\mathrm{CL}$ and $88 / 139(63.3 \%)$ had CLP; 86/139 (61.9\%) had unilateral defects, two cases had midline defects $(1.4 \%)$, and in $41 / 139(29.5 \%)$ the defect was bilateral. In 10 cases $(7 \cdot 2 \%)$ the nature of the lip defect was not recorded. In the unilateral CL[P] cases (where laterality was recorded) left sided defects were significantly more common, accounting for $55 / 86(63.9 \%)$ of this group $\left(\chi^{2}=6 \cdot 7, \mathrm{p}<0 \cdot 01\right)$.

\section{SEX DIFFERENCES (TABLE 2)}

There was a statistically significant excess of males $(90 / 139,64 \cdot 7 \%)$ among all CL[P] cases $\left(\mathrm{YM} \chi^{2}=8.36, \mathrm{p}<0.01\right)$ giving a male:female ratio (m:f) of $1 \cdot 84: 1$. This difference was almost entirely because of the male excess in $\mathrm{CL}[\mathrm{P}]$ cases with no associated abnormalities $\left(\mathrm{m}: \mathrm{f}=74: 29, \mathrm{YM} \chi^{2}=18.8, \mathrm{p}<<0.01\right)$. In the CP group $81 / 147(55 \cdot 1 \%)$ of all cases were female ( $\mathrm{m}: \mathrm{f}=0.81: 1, \mathrm{YM} \chi^{2}=3.11, \mathrm{p}>0.05$ ). Interestingly, the female excess in the CP group was most prominent in CP cases without associated abnormalities ( $\mathrm{m}: \mathrm{f}=0.65: 1)$ and in cases with Pierre-Robin sequence (PRS) without additional abnormalities (m:f $0 \cdot 36: 1$ ). These differences were not statistically significant.

Table 2 Sex distribution in the facial cleft subgroups

\begin{tabular}{lllll}
\hline Facial cleft & ICA Male & ICA Female & MCA Male & MCA Female \\
\hline CL[P] & $74^{*}$ & 29 & 16 & 20 \\
CL & $35^{*}$ & 11 & 3 & 2 \\
CLP & $39^{*}$ & 18 & 13 & 18 \\
CP (total) & 35 & 54 & 31 & 27 \\
Pierre-Robin sequence (PRS) & 5 & 14 & 4 & 0 \\
CP (excl PRS) & 30 & 40 & 27 & 27 \\
\hline
\end{tabular}

* Highly significant excess of male cases $(p<0.01) ; C L=$ cleft lip only; CLP $=$ cleft lip with cleft palate; $C L[P]=$ cleft lip with or without cleft palate; $C P=$ cleft palate only; ICA = cases in which the facial cleft was an isolated congenital anomaly; $M C A=$ cases in which the facial cleft was associated with another major congenital anomaly.
GEOGRAPHICAL AND SEASONAI DISTRIBUTION OF BIRTHS

Case distribution assessed by the Health Board of residence of the mother at the time of birth showed no statistically significant differences in TBP or LBP. There was no evidence of significant seasonal variation or cyclical trend in either group (data not shown).

\section{OUTCOME}

Thirteen of $139(9.3 \%)$ cases in the CL[P] group were stillborn; 10/126 (7.9\%) liveborn CL[P] cases had died by 1 January $1990 ; 8 / 10$ had major associated anomalies; $5 / 147(3.4 \%)$ cases in the CP group were stillborn; $14 / 142$ $(9.7 \%)$ of the liveborn children with CP had died by $01 / 01 / 90$ and all had major associated abnormalities. The proportions of stillbirths and early deaths were not significantly different in the two groups.

\section{ASSOCIATED ABNORMALITIES}

Thirty six of $139(25.9 \%)$ of the CL[P] group and $58 / 147(39.5 \%)$ of the CP group had one or more major congenital anomaly associated with their facial cleft. Minor congenital anomalies were present in an additional 12/139 $(8.6 \%) C L[P]$ and $28 / 147(19 \%) C P$ cases. Single gene defects, chromosomal aberrations and identifiable malformation syndromes accounted for $5.7 \%, 3.6 \%$ and $5.7 \%$ in the CL[P] group and $8 \cdot 2 \%, 5 \cdot 4 \%$, and $20.4 \%$ in the $\mathrm{CP}$ group respectively. In only one CP case was a teratogenic agent (ethanol) thought to be responsible for the facial cleft. A further 17/ $139(12.2 \%)$ in the CL[P] group and $22 / 147$ $(14.8 \%)$ of the CP group had associated major malformations that could not be identified as part of a particular syndrome. The remaining cases (10/48 CL[P] and 14/86 CP) had single associated minor abnormalities. The known diagnoses in both groups are summarised in table 3.

\section{Discussion}

Much of the data reported here are similar to those reported from other European populations. In particular, TBP of facial clefts, ${ }^{24163132}$ laterality of lip defects, ${ }^{1012}$ sex ratio differences of the subgroups, ${ }^{1012}$ and outcome data ${ }^{33}$ are apparently consistent findings that have been the subject of several excellent reviews ${ }^{101234}$ and, therefore, will not be discussed further. Our data, however, do differ significantly from previous reports in the proportion of cases with associated major congenital abnormalities (AMCA) and in the relative frequency of $\mathrm{CL}[\mathrm{P}]$ and $\mathrm{CP}$ in the cohort.

Comparing AMCA incidences between studies is difficult owing to the lack of a rigorous definition of terms used to describe such anomalies $^{35}$ (for example, uncomplicated micrognathia in Pierre-Robin sequence). However, given these limitations there is a remarkable range in the proportion of cases with AMCA between apparently well ascertained cohorts (table $4,2.9$ to $22.8 \%$ for CL[P] and 
Table 3 Genetic diagnoses in the facial cleft group

\begin{tabular}{|c|c|c|}
\hline Category & $\begin{array}{l}\text { Disorder in } C L / P] \\
\text { group }\end{array}$ & $\begin{array}{l}\text { Disorder in } C P \\
\text { group }\end{array}$ \\
\hline Autosomal dominant & $\begin{array}{l}\text { Myotonic dystrophy } \\
\text { Van der Woude syndrome (2) } \\
\text { Hay-Wells syndrome } \\
\text { Popliteal web syndrome } \\
\text { Greig syndrome }\end{array}$ & $\begin{array}{l}\text { Myotonic dystrophy } \\
\text { Van der Woude syndrome } \\
\text { Stickler syndrome (2) } \\
\text { Ectrodactyly-ectodermal } \\
\text { dysplasia-clefting syndrome } \\
\text { Velocardiofacial syndrome } \\
\text { Treacher Collins syndrome } \\
\text { Crouzon syndrome }\end{array}$ \\
\hline Autosomal recessive & $\begin{array}{l}\text { Hypertelorism-microtia- } \\
\text { clefting syndrome }\end{array}$ & $\begin{array}{l}\text { Campomelic syndrome } \\
\text { Diastrophic dysplasia } \\
\text { Kneist dysplasia }\end{array}$ \\
\hline $\begin{array}{l}\text { X linked } \\
\text { Chromosomal }\end{array}$ & $\begin{array}{l}\text { X linked hydrocephalus } \\
\text { Trisomy } 13(3) \\
46, X,+t(10 ; X) \\
46, X X, 3 q+\end{array}$ & $\begin{array}{l}\text { Orofaciodigital type I } \\
\text { Trisomy } 18(2) \\
\text { Trisomy } 18 \text { mosaic } \\
46, X Y, 9 p+ \\
46, X Y, t(3 ; 5 ; 9)+t(6 ; 17) \\
45, X,-9-X,+t(9 ; X) \\
46, X Y, \operatorname{del}(11)(q 21-23)\end{array}$ \\
\hline Malformation syndromes & $\begin{array}{l}\text { Schisis association (3) } \\
\text { Holoprosencephaly } \\
\text { 1st/2nd arch syndrome (2) } \\
\text { Di George syndrome } \\
\text { Dandy-Walker syndrome }\end{array}$ & $\begin{array}{l}\text { Schisis association (4) } \\
\text { Pierre-Robin sequence (23) } \\
\text { 1st/2nd arch syndrome (2) } \\
\text { VATER association }\end{array}$ \\
\hline
\end{tabular}

6.5 to $38.0 \%$ for $\mathrm{CP}$ ) with the present study appearing to have the highest incidence of AMCA (26\% CL[P] and $39.5 \% \mathrm{CP}$ ) among the groups chosen for comparison. Possible explanations for these differences will be discussed below. The nature of the AMCA reported in these studies is also of importance when comparing these data and may give clues to the pathogenesis of these disorders. This information has, however, been generally less well documented, presumably because of the heterogeneous nature of these anomalies. In the present study $55 \%(58 \%$ CL[P], $53.5 \%$ $\mathrm{CP}$ ) of the cases with AMCA had a cytogenetic, DNA based, or syndrome diagnosis leaving a significant minority of cases without a specific diagnosis. In a study of 1000 patients referred to a centre specialising in the treatment of craniofacial disorders, Shprintzen et $a l^{14}$ reported similar results with $41 \%$ of CL[P] and CP cases with AMCA having no specific diagnosis.

The $C L[P]: C P$ ratio provides a convenient method for observing differences in subgroup distribution between populations. In European populations the average TBP is about $1 \%$ for CL[P] and $0.5 \%$ for $\mathrm{CP}^{10}{ }^{12}$ thus giving a predicted CL[P]:CP ratio of approximately 2 . It is evident from the ratios derived from seven widely quoted reports (table 4) that the Scots and the Finns ${ }^{31}$ have significantly lower ratios than the rest of the group $(p<0.01)$. Other Scottish ${ }^{2223}$ and Finnish ${ }^{13}$ studies have shown similarly low $C L[P]: C P$ ratios. As the overall TBP in these reports are similar, it would appear that the altered $C L[P]: C P$ ratios in
Scotland and Finland are the result of both "too many" CP cases and "too few" CL[P] cases. The CL[P]:CP ratio of those cases with facial cleft as an isolated congenital anomaly (ICA) and those with AMCA were also compared (table 4). The CL[P]:CP ratio in the ICA group in all the studies was found to be higher than that in either the combined group or the AMCA group; however, the ratio in the Finns and the Scots remain significantly below the European average $(p<0.01)$. Interestingly, the ICA CL[P]:CP ratio from the Hungarian population $^{5}$ appears to be significantly higher $(p<0.01)$ than other reports.

There are three possible explanations for these results, none of which is mutually exclusive. Firstly the results could be artefactual, secondly, a specific environment influences the numbers of cases with AMCA and the $\mathrm{CL}[\mathrm{P}]: \mathrm{CP}$ ratio, and, thirdly, the differences are because of the populations being genetically heterogeneous. The studies chosen for comparison (table 4) used standard, multiple source techniques of ascertainment and were carried out by respected investigators so it would seem unlikely that the observed differences are the result of biased ascertainment.

Evidence that environmental or genetic factors or both may influence the CL[P]:CP ratio comes from a study in which Beckman and Myrberg $^{37}$ observed that it varied inversely with latitude in Sweden. They found the ratio to be $1.46: 1$ in northern counties, 1.82 :1 in central counties, and 3.72:1 in southern counties with similar TBP in each group. Thus the factors acting on the Scottish and Finnish populations producing low $\mathrm{CL}[\mathrm{P}]: \mathrm{CP}$ ratios may be a result of their location in northern latitudes. The lack of seasonal variation in both the present study and previous reports ${ }^{3940}$ however, implies that any exogenic factors acting on these populations are not directly related to temperature, weather, or daylight effects. Although the identification of specific environmental factors acting on populations has proven difficult, the reduction in recurrence of facial clefts born to women who had taken periconceptional multivitamin supplementation $^{41}$ may suggest an aetiological or corresponding role for dietary factors.

The regional differences in CL[P]:CP ratio and the proportion of facial cleft cases with AMCA could also reflect genetic differences in these populations. The prospect of elucidating such hereditary factors involved in facial clefting has been enhanced by the discovery of an association between both isolated CL[P] and

Table $4 C L[P]: C P$ ratios in European populations

\begin{tabular}{|c|c|c|c|c|c|c|}
\hline Study population & Year & $T B P$ & $\begin{array}{l}\text { Total No } C L / P]: C P \\
\text { cases }\end{array}$ & $\underset{\text { ratio }}{C L / P]: C P}$ & $\begin{array}{l}\text { No of cases with } A M C A \\
C L[P]: C P\end{array}$ & $\begin{array}{l}C L / P]: C P \text { ratio of cases } \\
\text { without } A M C A\end{array}$ \\
\hline $\begin{array}{l}\text { English }^{32} \\
\text { Canadian }^{36 *} \\
\text { Swedish }^{37} \\
\text { Finnish }^{31} \\
\text { Hungarian }^{5} \\
\text { French }^{4} \\
\text { Danish }^{38} \\
\text { Scottish } \dagger\end{array}$ & $\begin{array}{l}1962 \\
1969 \\
1972 \\
1974 \\
1980 \\
1982 \\
1988 \\
1992\end{array}$ & $\begin{array}{l}1.42 \\
1.63 \\
1.72 \\
1.69 \\
1.67 \\
1.52 \\
1.88 \\
1.53\end{array}$ & $\begin{array}{l}386: 188 \\
493: 244 \\
296: 140 \\
289: 298 \\
1407: 588 \\
121: 71 \\
492: 186 \\
139: 147\end{array}$ & $\begin{array}{l}2.05 \\
2.02 \\
2 \cdot 11 \\
0.97 \\
2.39 \\
1.71 \\
2.65 \\
0.94\end{array}$ & $\begin{array}{l}20: 23 \\
\text { NR } \\
\text { NR } \\
57: 66 \\
321: 223 \\
17: 27 \\
14: 12 \\
36: 58\end{array}$ & $\begin{array}{l}2 \cdot 21 \\
= \\
- \\
1 \cdot 00 \\
2 \cdot 97 \\
2 \cdot 36 \\
2 \cdot 74 \\
1 \cdot 16\end{array}$ \\
\hline
\end{tabular}

* These data refer to white (non-Indian) cases. $\uparrow$ Present study. $\mathrm{TBP}=$ birth prevalence per 1000 total births. $\mathrm{CL}[\mathrm{P}]=$ cleft lip with or without cleft palate. $\mathrm{CP}=$ cleft palate only. AMCA = associated major congenital anomalies. 
CP and a genetic variation in the TGF $\alpha$ gene. ${ }^{18-21}$ It may be possible in the future to show genetic differences between facial cleft groups in different populations that will explain the $C L[P]: C P$ ratio using this or other candidate gene probes. We are currently undertaking such a study in our population.

In conclusion, we cannot explain the differences in subgroup ratios and associated abnormalities found in European populations; however, it would appear that the commonly held assumption that there is little or no variation in the birth prevalence of $\mathrm{CP}^{910}$ is incorrect. To advance our understanding of the constellation of abnormalities that are associated with facial clefts it will be necessary to collect a large, well documented cohort of patients with facial clefts as part of multiple congenital anomalies in the hope that new diagnostic categories could be identified. This will certainly be a useful future role for projects such as the EUROCAT registers. Facial clefts have been one of the most intensely studied of human malformations with almost every report raising more questions than it has answered. This study follows the tradition and we hope that it will stimulate further research.

We would like to thank Drs John Tolmie and Rosemarie Davidson for their invaluable help with syndrome identification and $\mathrm{Dr}$ David Stone for access to information stored on the Glasgow EUROCAT register and Dr Susan Cole (CSA Trinity House, Edinburgh) for access to the SMR database information.

1 O'Rahilly R, Muller F. Development stages in human embryos. Washington: Carnegie Institute of Washington, 1987.

2 Fogh-Andersen P. Inheritance of hare lip and cleft palate. Copenhagen: Munksgaard, 1942.

3 Fujino H, Tanaka K, Sanui Y. Genetic studies of cleft lips and cleft palate based on 2828 Japanese cases. Kyushu $\mathcal{J}$ Med Sci 1963;14:317-31.

4 Bonaiti C, Briard ML, Feingold J, et al. An epidemiological and genetic study of facial clefting in France. I Epidemiology and frequency in relatives. $\mathcal{f}$ Med Genet 1982;19:8 15.

5 Czeizel A. Cleft lip and cleft palate in East European populations. In: Melnick M, Bixler D, Shields ED, eds. Etiology of cleft lip and cleft palate. New York: Alan R Liss, 1980:249-96.

6 Neel JV. A study of major congenital defects in Japanese infants. Am $\mathcal{f}$ Hum Genet 1958;10:398-445.

7 Tretsven VE. Incidence of cleft lip and palate in Montana Indians. $\mathcal{f}$ Speech Hear Disord 1963;28:52-7.

8 Longnecker CG, Ryan RF, Vincent R. The incidence of cleft lip and cleft palate in Charity Hospital. Plast Reconstr Surg 1965;35:548-50.

9 Chung CS, Myrianthopoulus NC. Racial and prenatal factors in major congenital malformations. $\mathrm{Am} \mathcal{f ~ H u m}$ Genet $1968 ; 20: 44-60$.

10 Shapiro BL. The genetics of cleft lip and palate. In: Stewart RE, Prescott GH, eds. Oral facial genetics. St Louis: Mosby, 1976:473.

11 Tenconi R, Clementi M, Turolla L. Theoretical recurrence risk for cleft lip derived from a population of consecutive newborns. $\mathcal{f}$ Med Genet 1988;25:243-6.

12 Fraser FC. The genetics of cleft lip and cleft palate. $A m \mathcal{J}$ Hum Genet 1970;22:336-52.

13 Rollnick BR, Pruzansky S. Genetic services at a centre for craniofacial anomalies. Cleft Palate f 1981;18:304-13.

14 Shprintzen RJ, Seigel-Sadewitz VL, Amato J, Goldberg RB. Anomalies associated with cleft lip, cleft palate or both. Am $\mathcal{f}$ Med Genet 1985;20:585-95.

15 Woolf CM. Congenital cleft lip. f Med Genet 1971;8:65-71. 6 Rintala AE. Epidemiology of orofacial clefts in Finland: a review. Ann Plast Surg 1986:17:456-9.

17 Van der Woude A. Fistula labii inferioris congenita and its association with cleft lip and palate. Am $\mathcal{f}$ Hum Genet 1954;6:244-56.

18 Ardinger HH, Buetow KH, Bell GI, Bardach J, VanDemark DR. Association of genetic variation of the transmark DR. Association of genetic variation of the transforming growth factor-alpha gene with

19 Chenevix-Trench G, Jones K, Green A, Martin N. Further evidence for an association between genetic variation evidence for an association between genetic variation
between transforming growth factor alpha and cleft lip and palate. Am f Med Genet 1991;48:1012-13.

20 Holder SE, Vintiner GM, Malcolm S, Winter R. Nonsolder SE, Vintiner GM, Malcolm S, Winter R. Non-
syndromic cleft lip and palate: association and linkage studies with the TGF alpha gene. HGM11. Cytogenet Cell Genet 1991;58:1869A.

21 Shiang R, Lidral AC, Ardinger HH, Murray JC, Buetow $\mathrm{KH}$. Association of TGFA DNA variants with cleft lip and palate. HGM11. Cytogenet Cell Genet 1991;58:1872A.

22 Drillien CM, Ingram TTS, Wilkinson EM. The causes and natural history of cleft lip and palate. Edinburgh: Churchill-Livingstone, 1966.

23 Womersley J, Stone DH. Epidemiology of facial clefts. Arch Dis Child 1987;62:717-20.

24 Bagatin M. Cleft uvula. Acta Chir Plast 1985;27:202-6.

25 Bagatin M. Submucous cleft palate. f Maxillofac Surg 1985;13:37-8.

26 Iizuka T. High incidence of cleft lip and cleft palate in the human embryo and early fetus. Okajimus Folia Anat fap 1973;50:259-71.

27 Czeizel A, Tusnady G. Isolated common congenital abnormalities in Hungary. Budapest: Akademiai Kiado, 1984.

28 Edwards JH. The recognition and estimation of cyclic trends. Ann Hum Genet 1961;25:83-7.

29 Hewitt D, Milner J, Csima A, Pakula A. On Edwards' criterion of seasonality and a non-parametric alternative. Br F Prev Soc Med 1971;25:174-6.

$30 \mathrm{Smith} \mathrm{DW}$. Classification, nomenclature and naming of morphologic defects. 7 Pediatr 1975;87:162.

31 Saxen I, Lahti A. Cleft lip and palate in Finland: incidence, secular, seasonal, and geographical variations. Teratology 1974;9:217-23.

32 Knox G, Braithwaite F. Cleft lips and palates in Northum berland and Durham. Arch Dis Child 1963;38:66-70.

33 Mackeprang M, Hay S. Cleft lip and palate mortality study. Cleft Palate f 1972;9:51.

34 Warkany J. Malformations of the face. In: Congenital malformations: notes and comments. Chicago: Year Book Medical Publishers, 1971:621.

35 Sayetta RB, Weinrich MC, Coston GN. Incidence and prevalence of cleft lip and palate: what we think we know. Cleft Palate f 1989;26:243-7.

36 Lowry RB, Renwick DHG. Incidence of cleft lip and palate in British Columbia Indians. $\mathcal{F}$ Med Genet 1969;6:67-9.

37 Beckman L, Myrberg N. The incidence of cleft lip and palate in northern Sweden. Hum Hered 1972;22:417-22.

38 Jensen BL, Kreiborg S, Dahl E, Fogh-Andersen P. Cleft lip and palate in Denmark, 1976-1981: epidemiology, vari1988;25:258-69.

39 Lutz KR, Moor FB. A study of factors in the occurrence of cleft palate. $\mathcal{F}$ Speech Dis 1955;20:271.

40 Fraser GR, Calnan JS. Cleft lip and palate: seasonal incidence, birth weight, birth rank, sex, site, associated malformations and parental age. Arch Dis Child 1961;36:4203 .

41 Tolarova $M$. Periconceptual supplementation with vitamins and folic acid to prevent the recurrence of cleft lip. Lancet 1982;ii:217. 